\title{
INTERNACIONALIZACIÓN E RESPONSABILIDADE SOCIAL CORPORATIVA DA BANCA ESPAÑOLA EN AMÉRICA LATINA.
}

Pablo Rodríguez-Gutiérrez ${ }_{2}$ Fernando Fuentes-García a, Sandra Sánchez-Cañizares a, Mercedes Luque-Vílchez, ${ }^{\mathrm{b},}$ a Departamento de Organización de Empresas, Universidade de Córdoba, España b Departamento de Contabilidade, Universidade de Burgos, España

* Corresponding author: Mercedes Luque-Vilchez, mlvilches@ubu.es

RESUM0: Os procesos de liberalización económica acontecidos tanto en Europa como en América Latina fixeron que o sector financeiro español elixa estas rexións para expandir a súa actividade. Ao adquirir unha dimensión internacional, a banca española adoptou un papel de liderado. Este feito, unido ao xa de por si importante papel que xogan as finanzas para 0 desenvolvemento da economía fai que sexa necesario que estas entidades desenvolvan a súa actividade de maneira responsable. Este traballo analiza a xestión dos aspectos sociais e medioambientais por parte da banca española, concretamente analízase o caso do comportamento social e medioambientalmente responsable do Banco Santander e BBVA no seu proceso de internacionalización. Próbase neste estudo que as iniciativas concretas que xurdiron coa finalidade de fomentar a institución da RSC nas entidades financeiras son moi heteroxéneas entre elas. Malia estar asistindo nos últimos anos a un impulso no número de publicacións relativas á RSC, a meirande parte ocúpase dos impactos internos das operacións bancarias, así como das actividades de tipo filantrópico.

Palabras chave: Internacionalización, Entidades financeiras, RSC, España, América Latina. JEL: M16, Q56.

INTERNATIONALIZATION AND CORPORATE SOCIAL RESPONSIBILITY OF THE SPANISH BANKING SECTOR IN LATIN AMERICA.

ABSTRACT: The economic liberalization processes that have taken place in both Europe and Latin America have led the Spanish financial sector to choose these regions to expand its activity. The adoption of an international dimension has allowed Spanish banks to take a leading role. This fact, together with the already important role played by finances for the development of the economy, makes it necessary for these entities to carry out their activities in a responsible manner. This paper analyzes the management of social and environmental aspects by the Spanish banking sector, specifically analyzing the case of socially and environmentally responsible behavior of Banco Santander and BBVA in their internationalization process. This study proves that the specific initiatives that have emerged with the aim of promoting the implementation of CSR in financial institutions are very heterogeneous. Despite the fact that in recent years there has been an increase in the number of publications related to CSR, most of them deal with the internal impacts of banking operations and philanthropic activities.

Key words: Internationalization, banking industry, CSR, Spain, Latin America. JEL: M16, Q56.

\section{INTRODUCIÓN}

A responsabilidade social nace como resposta a unha concepción de empresa que quedou obsoleta para explicar o papel da empresa no novo modelo económico. O papel da empresa como un sistema pechado, que só responde perante os seus propietarios e que só se debe preocupar de maximizar os seus beneficios queda obsoleto. Perante un novo modelo económico no que o papel da empresa se fai cada vez máis decisivo e a sociedade cada vez máis esixente para con ela fai que sexa necesario un cambio de filosofía que 
integre na xestión da empresa e nos seus obxectivos os desexos de pretensións de todos os elementos sociais que se ven afectados pola súa actividade. É por iso que nace un modelo de empresa aberto no que non só se teñen en conta os resultados económicos senón que ademais se integren nos obxectivos da empresa outros de natureza social e medioambiental, tomando consciencia de que só mediante a procura do ben común se consegue o beneficio propio de maneira duradeira.

Os procesos de liberalización económica acontecidos tanto en Europa como en América Latina fixeron que o sector financeiro español dentro da corrente xeral de internacionalización, elixira estas rexións para expandir a súa actividade, sobre todo en América Latina coa que España comparte unha historia, lingua e cultura común. Esta expansión seguiu un ronsel de éxitos que levaron aos grandes bancos españois a se converteren nuns dos maiores do mundo e líderes naquela zona. Este papel de liderado unido ao de por si importante papel que xogan as finanzas para o desenvolvemento da economía fai que sexa máis, se cabe, necesario que estas entidades leven a cabo a súa actividade de maneira responsable.

As entidades financeiras son conscientes da súa responsabilidade, que trascende a xestión interna do seu negocio chapicando de forma indirecta a toda a sociedade, por iso é que están implicadas na tarefa de aplicar a filosofía de responsabilidade social corporativa á súa xestión. Esta implementación, dentro da estratexia corporativa, de valores responsables foi feita principalmente por unha serie de guías elaboradas por entidades privadas como a Global Reporting Initiative.

O sistema financeiro ten a encomenda de canalizar o aforro cara o investimento poñendo en relación numerosos stakeholders. O sistema financeiro débese desenvolver ao mesmo tempo que o fai o resto da economía. Deste modo, o sistema financeiro dinamizará o proceso de crecemento. Como indica Calvo, Parejo, Rodríguez e Cuervo (2010), a vantaxe desta función de transformación é a de captar uns fondos que non serían utilizados, agás se unhas institucións os tomasen como depósitos, previo pagamento dun interese, a fin de que estas mesmas institucións os poidan emprestar, á súa vez, cobrando outro tanto. Todos os fondos recollidos a curto prazo e a súa capacidade potencial e real de ser emprestados a medio e longo prazo cumpren un labor fundamental, o de propiciar 0 investimento e con iso o crecemento económico.

As entidades de crédito xestionan riscos non só económicos, senón tamén sociais e medioambientais e ademais deben responder ao reclamo dunha sociedade cada vez máis preocupada polo destino do seu aforro (De la Cuesta, 2006). Así o confirman Ortiz e Cordero (2007), segundo os cales, malia que o sector financeiro foi tradicionalmente obxecto de fortes críticas pola súa falla de compromiso co desenvolvemento social e 0 enfoque centrado na obtención de beneficios, o certo é que na súa actividade ten un impacto social de gran magnitude, pois os bancos fan posible a canalización dos recursos económicos cara ás actividades máis produtivas, o que permite, á súa vez, xerar maiores niveis de produtividade, emprego, crecemento económico e benestar social.

A importancia que ten o sector bancario no conxunto da economía fai que a súa responsabilidade trascenda a súa actividade interna e se centre máis na influencia que exerce sobre o conxunto da sociedade de maneira indirecta. A maior importancia do estudo da responsabilidade social no caso da banca estará no seu papel indirecto como intermediario e non tanto no impacto directo da propia actividade. Polo tanto, ao analizar a RSC nas EE.FF. e, en particular, nas entidades bancarias, distínguese unha dupla 
dimensión dos seus impactos económicos, sociais e medioambientais (De la Cuesta, 2004 e Muñoz, Fernández e De la Cuesta 2004):

- Dimensión interna da RSC: refírese aos impactos indirectos derivados do seu comportamento con relación aos diferentes grupos de interese, e tamén ao seu compromiso de "acción social" a favor da colectividade.

- $\quad$ Dimensión externa da RSC: refírese aos impactos indirectos de RSC que resultan do papel que desempeñan os bancos ao canalizar o aforro cara ás actividades de investimento ou de consumo.

Polo tanto, no momento de avaliar a actuación no eido da RSC das entidades bancarias haberá que ter en conta non só os aspectos internos da súa xestión do negocio, senón que ademais terán que se ter en conta os impactos sociais e medioambientais das actividades de investimento financiadas.

O contexto económico, político e social caracterízase hoxe en día por un maior nivel de complexidade, interdependencia e flexibilidade que propiciou que as relacións entre distintos países se intensifiquen e como mellor expoñente deste proceso está a internacionalización das economías e das súas empresas (Chevalier, 1995; Dunning, 1994 e Ohmae, 1991). Neste proceso de abertura de mercados e de maior grao de internacionalización, as relacións financeiras convertéronse nun aspecto central, e manifestáronse máis relevantes que as produtivas ${ }^{1}$, subordinando a elas as políticas de orientación produtiva e comercial, o que provocou que sectores relacionados coas actividades financeiras viran aumentado o seu poder. A importancia do sector servizos é cada vez máis evidente no conxunto da economía representando o $70 \%$ do produto interior bruto mundial.

O resto do artigo está estruturado da seguinte maneira: a segunda sección amosa en conxunto as relacións existentes entre a RSC e a internacionalización na banca. A terceira sección describe o enfoque metodolóxico adoptado na investigación empírica. A cuarta sección adícase á análise das memorias de RSC, tomando como representantes da banca española aos bancos Santander e BBVA; e, finalmente, a quinta sección, os comentarios principais.

\section{A BANCA ESPAÑOLA: RSC E INTERNACIONALIZACIÓN}

Para o caso da banca española parece claro que deberían ser de obrigado cumprimento as pautas da RSC, porque o seu carácter de prestación de servizos e de captación de aforro e crédito dos cidadáns ten un carácter regulado. O carácter aberto dos seus servizos implicaría a a falla de obriga no seu cumprimento, pero o carácter xeral do servizo prestado a as desigualdades sociais da zona aconsellan que estas EE.FF. adquiran o seu compromiso co cumprimento da RSC. Ademais, se a IED vai acompañada pola asunción de maneira total ou parcial de medidas e políticas de responsabilidade social, sería positivo para apoiar a estabilidade económica, social e o desenvolvemento dos países da rexión. Pódese afirmar que a banca, ao configurarse como un sector estratéxico tanto para España como para os países onde se instala, reflicte o compromiso de permanencia e de traballo a longo prazo (Becker, 2002), compromiso que se pode constatar mediante unha acción responsable e transparente.

\footnotetext{
${ }^{1}$ As políticas económicas dos gobernos dan maior prioridade a aspectos monetarios como son os prezos, os tipos de interese e o tipo de cambio, facendo da estabilidade monetaria o obxectivo esencial da política económica.
} 
O papel das empresas na economía actual, no que xogan un rol cada vez máis decisivo, como é o caso da banca española no seu proceso de internacionalización, substituíndo aos Estados en moitos casos, fai que a responsabilidade perante a sociedade sexa no futuro un imperativo básico para as empresas. O sector financeiro español non foi alleo a este proceso e viu elevados de forma exponencial os niveis de investimentos fóra das fronteiras nacionais na procura de expandir cara outros mercados nas últimas décadas, sobre todo en América Latina, chegando a acadar unha posición de liderado.

O grao de internacionalización bancaria, como indican Durán e Lamothe (1991: 188), "está determinado polo nivel de diversificación xeográfica acadado a través das súas filiais no exterior, sendo secundaria a distribución internacional da propiedade".

Táboa 1. Composición de activos de bancos globais en 2009.

\begin{tabular}{|l|c|c|c|}
\hline & $\begin{array}{c}\text { Activos en América } \\
\text { Latina }\end{array}$ & Activos no mundo & $\begin{array}{c}\text { América Latina / Total } \\
(\%)\end{array}$ \\
\hline Banco Santander & 213.753 & 1.110 .529 & 19,25 \\
\hline BBVA & 102.191 & 535.065 & 19,1 \\
\hline Citigroup & 46.923 & 1.428 .189 & 3,29 \\
\hline Total & 362.867 & 3.073 .783 & 11,80 \\
\hline
\end{tabular}

Fonte: memoria anual de ámbalas dúas entidades (2009). Datos de activos expresados en millóns de euros.

En comparación coa porcentaxe de participación dos activos en América Latina sobre o total das entidades calculado para 2002 por Ballescá (2007) dedúcese unha diminución da participación dos mesmos. Banco Santander pasa do 29,2\% ao 19,25\% e BBVA pasa do $26,1 \%$ ao 19,1\%. Isto pode obedecer a unha xestión máis axeitada do risco diversificando a repartición dos investimentos das EE.FF. entre varios mercados, en concreto un maior investimento nos países da Europa comunitaria. Malia isto, o grao de compromiso con América Latina segue sendo elevado. Este grao de compromiso é o que fixo que a banca española sexa xunto á estadounidense o principal investidor exterior no seu sector, seguidos de lonxe pola banca británica. No proceso de internacionalización vivido en América Latina, seis foron os bancos que tomaron posicións na zona, principalmente 0 Santander, BBVA, Citibank, e en menor medida HSBC, Scoticbank e ABN Ambro². Como resumo, preséntase a seguinte táboa:

Táboa 2. Principais EE.FF. estranxeiras en América Latina.

\begin{tabular}{|l|l|}
\hline \multicolumn{1}{|c|}{ Entidade } & \multicolumn{1}{c|}{ País de Orixe } \\
\hline Banco Santander & España \\
\hline BBVA & España \\
\hline Citibank & Estados Unidos \\
\hline HSBC & Reino Unido \\
\hline Scotiabank & Canadá \\
\hline
\end{tabular}

${ }^{2}$ Entidade adquirida en parte polo Banco Santander, obtendo a súa participación en Brasil. 
Fonte: Elaboración propia a partir de Ballescá (2007).

Por volume de activos na rexión, a banca española, o Santander e o BBVA, están nas primeiras posicións, seguidos de lonxe polo Citibank, que non chega a representar nin a cuarta parte dos activos de Banco Santander na rexión.

Estas tres entidades, que son líderes en América Latina, sumaban en total 362.867 millóns de euros en activos na rexión a finais de 2009 (México, Porto Rico, Colombia, Venezuela, Brasil, Uruguai, Arxentina, Chile, Perú e Colombia), namentres que para esa mesma data 0 produto interior bruto para eses países foi de 3.168.776,85 millóns de euros, co cal os activos dos principais bancos internacionais en América Latina, representan o 11,5\% do PIB deses países, o que pon de relevo o gran peso destas entidades para a economía da zona.

Concretamente, os grandes bancos españois ( Santander e BBVA) manteñen unha situación preponderante nos mercados latinoamericanos ocupando o primeiro e segundo posto respectivamente como as EE.FF. transnacionais con maior número de activos na zona, concentrando o $10 \%$ e o $9 \%$ do sistema financeiro latinoamericano.

O elevado grao de compromiso, investindo gran parte dos seus activos na zona, debería de servir de motivo para que a gran banca española asuma sucesivamente maiores niveis de responsabilidade nos mercados nos que actúa.

Nos últimos anos estamos asistindo a un proceso no cal a emisión do informe de responsabilidade social se asume como unha práctica máis da empresa (Higgins e Larrinaga, 2014), o que conforme a Moneva (2005) é debido a varios factores:

- A implicación institucional, nacional e internacional: libro verde da Comisión Europea (2004), Pacto Mundial das Nacións Unidas.

- $\quad$ A presión dos mercados, especialmente a través de mecanismos como os índices de sustentabilidade como Dow Jones Sustainability, FTSE4GOOD.

- O xurdimento de propostas que facilitan a elaboración de informes e a homoxeneización da información.

A pesar destes esforzos, para Cea (2010) é pouco frecuente que se ofreza información sobre os impactos indirectos da RSC das operacións bancarias, ou o que é o mesmo, os criterios de sustentabilidade que a banca ten establecidos para decidir sobre 0 financiamento de proxectos de investimento, da súa contribución ao desenvolvemento sostible a través dos recursos financeiros asignados a tales fins.

A continuación, recóllense as epígrafes máis significativos sobre a información de RSC ofrecida polo Banco Santander e BBVA nas súas memorias. O criterio empregado na maioría dos casos para avaliar a importancia que se outorga á información é se se aportaron datos para a súa posible cuantificación e comparabilidade, máis aló de aportar unha mera declaración de intencións ou unha simple descrición de feitos.

\section{METODOLOXÍA}

En primeiro lugar, grazas a unha revisión detallada da literatura previa establécese a conexión teórica entre Responsabilidade Social Corporativa en entidades financeiras e internacionalización. A continuación, lévase a cabo unha análise dos informes de RSC presentados pola gran banca española (Banco Santander e BBVA) que polas súas 
dimensións e peso dentro do seu sector e da economía en xeral representan o que pode ser o paradigma de empresa internacional e responsable.

En concreto, a análise da actuación responsable levouse a cabo mediante o estudo comparativo das memorias publicadas polas entidades correspondente aos anos 2006, 2007, 2008 e 2009 e con especial referencia aos aspectos destacados sobre a súa actividade en América Latina.

A análise amosará a situación dos contidos que aparecen nos informes. A través da información publicada nas memorias de RSC de cada ano, ponse de manifesto os avances feitos no seu desempeño económico, social e medioambiental, outorgando un maior grao de transparencia ao traballo realizado pola entidade. Asemade, analizaremos o que a entidade entende o que é a RSC na banca. Para iso trátase de analizar e clasificar o contido das memorias de RSC atendendo a unha serie de trazos característicos.

Os contidos informativos recollidos nas memorias de responsabilidade social van facer referencia ao ano 2009, e a metodoloxía de clasificación de información sobre responsabilidade social empregada segue á exposta por Cea (2010) no Anexo 1. Para a súa análise tabuláronse os resultados observados comparando os resultados obtidos entre 0 Banco Santander e o BBVA3.

A análise amosará a situación dos contidos que aparecen nos informes. A través da información publicada nas memorias de RSC de cada ano, ponse de manifesto os avances feitos no seu desempeño económico, social e medioambiental, outorgando un maior grao de transparencia ao traballo realizado pola entidade. Asemade, analizaremos o que a entidade entende o que é a RSC na banca. Para iso trátase de analizar e clasificar o contido das memorias de RSC atendendo a unha serie de trazos característicos.

\section{ANÁLISE}

A continuación, recóllense distintas epígrafes sobre a información de RSC ofrecida polo Banco Santander e BBVA nas súas memorias. O criterio empregado na maioría dos casos para avaliar a importancia que se outorga á información é se se aportaron datos para a súa posible cuantificación e comparabilidade, máis aló de aportar unha mera declaración de intencións ou unha simple descrición de feitos.

O primeiro punto á hora de analizar a RSC das entidades é ver cal é a repartición funcional feita do investimento en responsabilidade social (gráfico 1), coa finalidade de saber en que aspectos as entidades poñen maior énfase. no caso do Banco Santander faise un especial énfase en aspectos educativos de responsabilidade social, máis concretamente no compromiso que a entidade ten coas Universidades a través da creación da rede Universia da que falaremos máis adiante. No caso do BBVA, o esforzo investidor é máis equilibrado adicando máis cantidade de recursos á acción social ${ }^{4}$ e cultural fronte ao aspecto educativo. En ámbolos dous casos, a área medioambiental queda reducida a unha parte marxinal.

\footnotetext{
3 Os enunciados dalgunhas das súas tábaos recóllense no anexo 2.

4 As principais áreas de acción que se poden distinguir na RSC son social e medioambiental, malia que se decidiu tratar os aspectos educativos da acción social de forma independente pola súa grande importancia relativa.
} 
Gráfico 1. Investimento en RSC por áreas de interese do grupo Santander e BBVA.

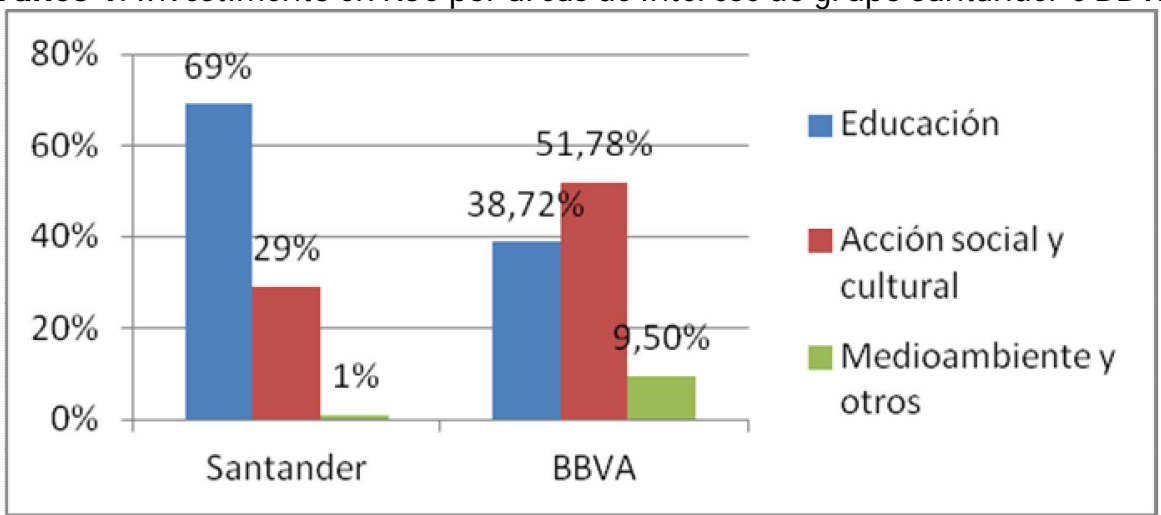

Fonte: Elaboración propia a partir da memoria de responsabilidade de 2009.

Na seguinte táboa, exponse o volume de gasto en RSC con respecto ao total de beneficios obtidos polo Santander e BBVA. Hai que destacar que, malia que o volume de recursos foi en aumento ao longo dos anos, en ámabalas dúas entidades, o comportamento que tivo con respecto ao crecemento dos beneficios foi desigual. A este investimento en RSC habería que engadir os efectos positivos da IED sobre as nacións de destino da mesma (explicado na sección anterior).

No caso do Banco Santander o investimento nestes últimos 5 anos baixou á metade (do $2,33 \%$ ao $1,41 \%$ dos beneficios), o caso contrario ocorreu co BBVA que, logo duns primeiros anos de indefinición, experimentou na partida de RSC un crecemento extraordinario aumentando así o compromiso coa sociedade e o medioambiente (do $1,13 \%$ ao $1,90 \%$ dos beneficios).

Hai que destacar que o retorno á sociedade en forma de investimento en medidas de RSC é superior, o 1,2\% do beneficio, fronte a un hipotético 0,7\% do PIB das nacións desenvolvidas, esixido por diversos organismos para destinar a proxectos de desenvolvemento en países en vías de desenvolvemento. Actualmente os países desenvolvidos comprométense a destinar o 0,15\% do seu PNB á axuda ao desenvolvemento. No caso de España, a axuda oficial ao desenvolvemento (AOD) acada para 2008 a cifra do 0,43\% do PNB (Ministerio de asuntos exteriores e cooperación), moi lonxe do aportado pola empresa privada a través das súas políticas de RSC.

Táboa 3. O gasto en acción social e RSC das multinacionais españolas.

\begin{tabular}{|l|c|c|c|c|c|c|c|}
\hline Empresa multinacional & 2004 & 2005 & 2006 & 2007 & 2008 & 2009 & $\begin{array}{c}\text { \%RSC sobre } \\
\text { beneficios (2009) }\end{array}$ \\
\hline BBVA & 38,3 & 46 & 56 & 69 & 85 & 80 & $1,9 \%$ \\
\hline Banco Santander & 84 & 92 & 106 & 119 & 126 & 126 & $1,41 \%$ \\
\hline Total & 236,5 & 252,7 & 292,9 & 369,8 & 211 & 206 & \\
\hline
\end{tabular}


Todos os datos están en millóns de euros. Fonte: Elaboración propia a partir dos informes anuais das empresas (2008).

Gráfico 2. Ratio Investimento en RSC/ Beneficio

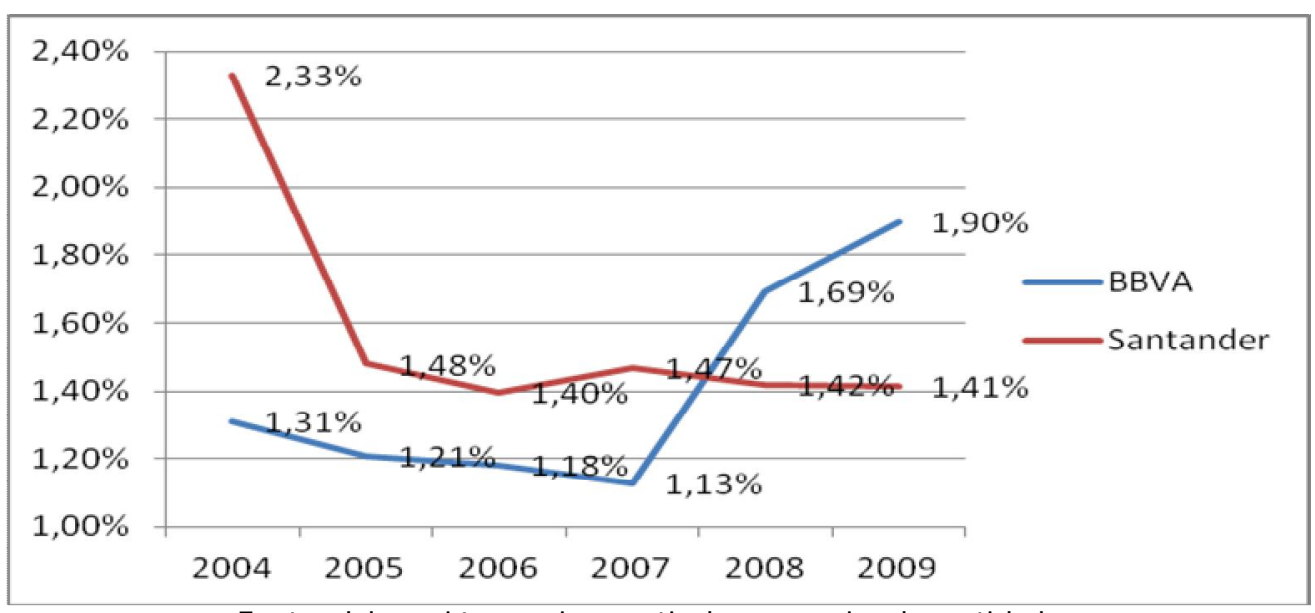

Fonte: elaboración propia a partir das memorias das entidades.

Ao ver a seguinte táboa, poderíase pensar que o BBVA destina lixeiramente algo máis a América Latina no seu esforzo por ser máis responsable, pero sorprende o feito na forma en que se reparte o investimento en RSC por área xeográfica, en relación á súa importancia dentro do negocio global.

No caso do BBVA, América Latina representa o 43,5\% do seu beneficio e, porén, destinou 0 $40,5 \%$ dos fondos a esta zona. No caso do Banco Santander, América Latina apórtalle un $36 \%$ do beneficio total co cal destina á rexión máis do que lle correspondería por beneficios. Se poñemos en relación o beneficio obtido e o investimento realizado en RSC por área xeográfica, a proporción entre ámbolos dous aumenta para América Latina. Nembargantes, para o caso do Banco Santander esta cifra en liñas xerais representaba 0 1,41\% para América Latina, e a cifra ascende ata o 1,58\% do beneficio.

\subsection{Clientes}

Logo desta descrición xeral da clientela (distribución por área xeográfica e por tipo de negocio ao que pertence), fíxanse cales son os principais obxectivos neste campo: calidade do servizo, satisfacción, incidencias e reclamacións, accesibilidade multicanle.

En canto á calidade do servizo, satisfacción e incidencias e reclamacións, as entidades céntranse en analizar nas súas memorias de responsabilidade dous elementos, por unha banda, examinan o nivel de satisfacción dos seus clientes e, por outra, avalían as queixas e reclamacións que realizan. En canto ao nivel de satisfacción nos Gráfico 14 e Gráfico 15 correspondentes ao Santander e ao BBVA, obsérvase como en ámbalas dúas entidades o nivel de satisfacción da clientela co servizo prestado pola súa entidade é superior en 
América Latina sobre os niveis observados en España, sede principal de ámbalas dúas entidades.

Gráfico 3. Nivel de satisfacción clientes Banco Santander

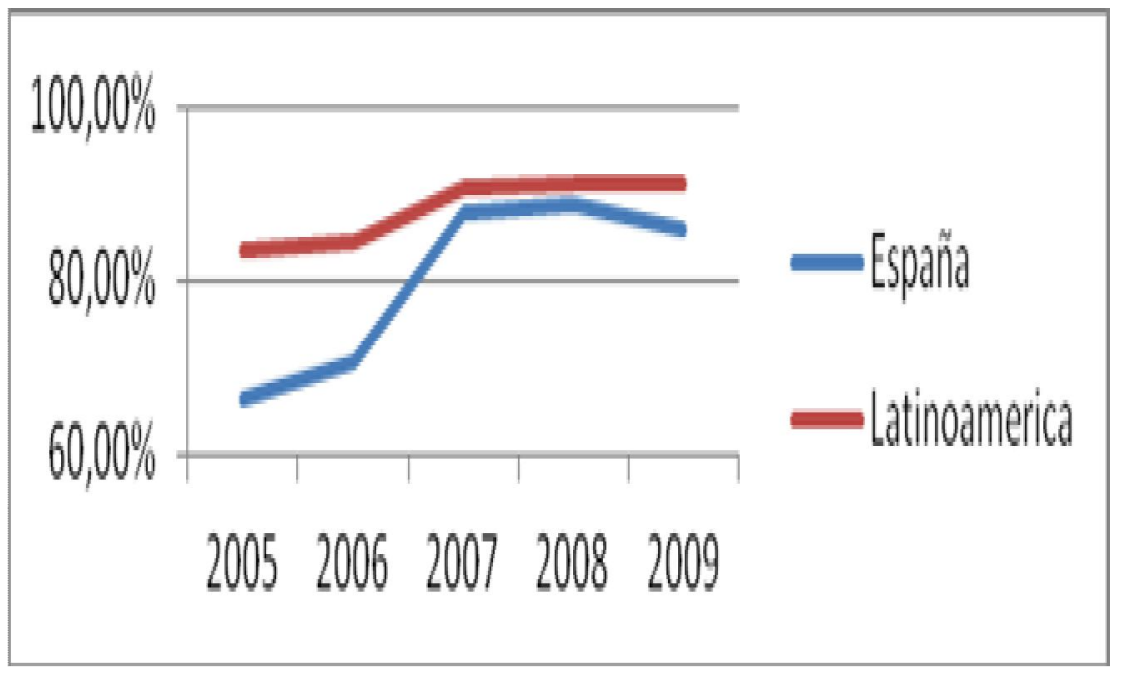

Gráfico 4. Nivel de satisfacción clientes BBVA.

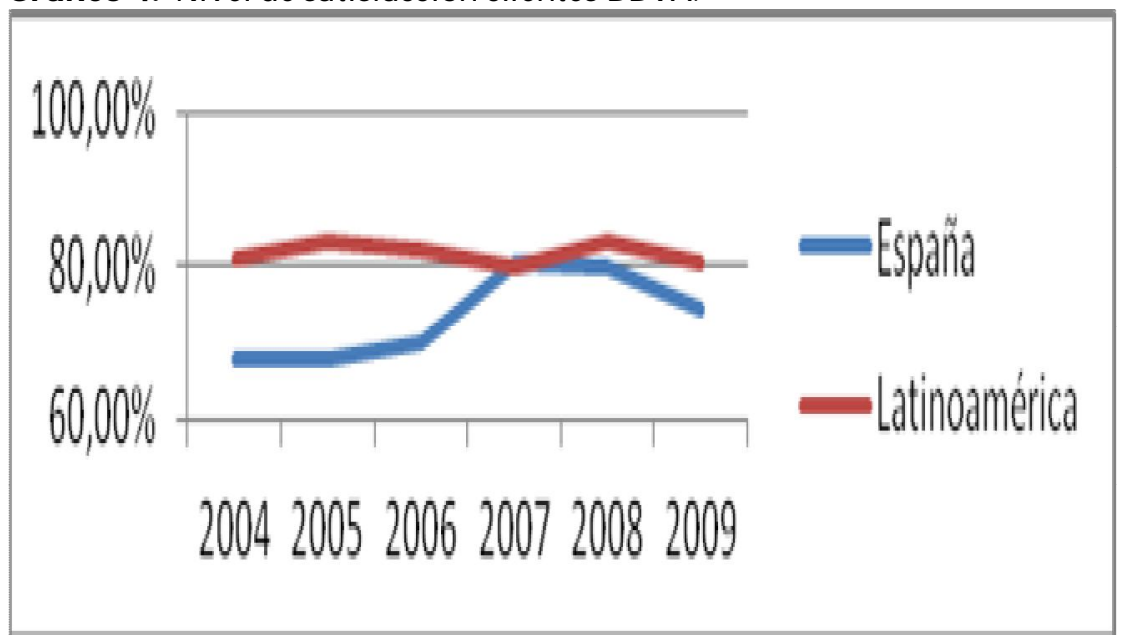

Fonte: elaboración propia a partir das memorias de responsabilidade do Banco Santander e do BBVA.

En canto ao volume de reclamacións, pódese afirmar que se atopan en relación directa co nivel de satisfacción, xa que se é elevado o número de reclamacións será menor o nivel de satisfacción. No Gráfico 16 obsérvase como, contraditoriamente, o nivel de reclamacións en todo o período analizado é maior no mercado latinoamericano. Aprecíase un elevado 
aumento nos anos 2007 e 2008, que poden chegar a distorcer a comparación, e que se refire a unha campaña gobernamental en Venezuela para fomentar o uso das reclamacións contra o Banco Santander, que finalmente foi nacionalizado en xullo de 2009. Estes datos contradín os anteriores de satisfacción do cliente. Unha posible causa residiría en que malia o maior númçero de reclamacións, alas son escoitadas pola entidade dando solucións ao cliente.

Gráfico 5. Porcentaxe de reclamacións por cliente Banco Santander.

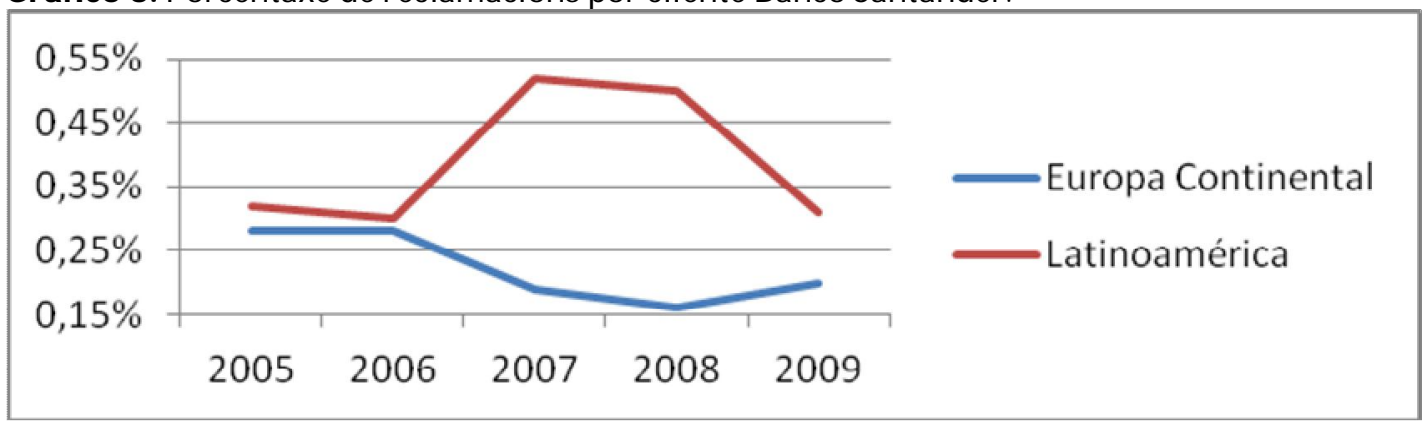

Fonte: elaboración propia a partir das memorias de responsabilidade do Banco Santander.

Por outra banda, outra das preocupacións das entidades estriba na accesibilidade ou facilidade para acceder que poidan ter os clientes aos servizos ofrecidos. Para iso, destácase o número de oficinas e número de caixeiros automáticos, así como o volume de transaccións por medios alternativos como teléfono e internet. No caso do Banco Santander, pódese ver nos Gráficos 6 e 7 as diferenzas e tendencias comparadas entre España e América Latina. O primeiro que se observa é que o modelo de negocio en España é moito máis intensivo en número de oficinas por número de clientes, cunha media de 3.000 clientes por oficina, cifra que descendeu en 2008 pero que se volveu recuperar debido ao peche de oficinas a causa da crise. América Latina presenta unha menor porcentaxe de oficinas por número de clientes, o que se ve cunha cifra de 5.000 clientes por oficina en 2006, cifra en aumento ata preto dos 7.000 para 2009, o que queda lonxe de amosar o maior empeño por facilitar o achegamento da entidade ao cliente.

Gráfico 6. Clientes por oficina. Banco Santander. 


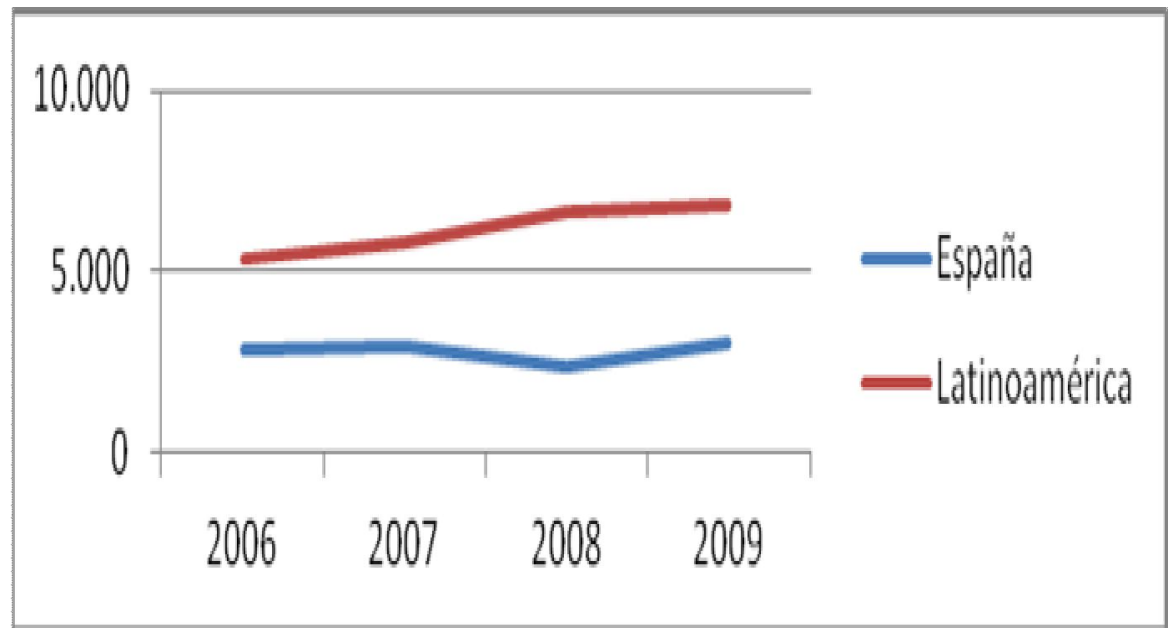

Fonte: elaboración propia a partir das memorias de responsabilidade do Banco Santander.

Gráfico 7.Clientes por caixeiro automático. Banco Santander.

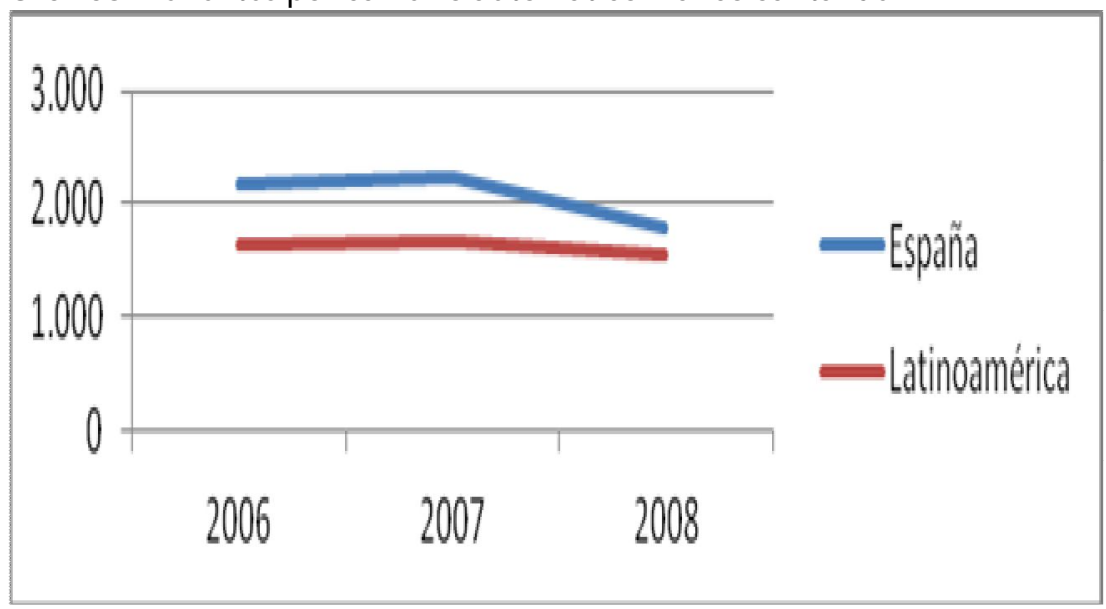

Fonte: elaboración propia a partir das memorias de responsabilidade do Banco Santander.

O obxectivo de facilitar o acceso dos clientes ás xestións bancarias parece que se procura acadar non tanto pola vía de abrir máis oficinas, senón máis ben a través do aumento do número de caixeiros automáticos. Neste senso América Latina presenta unha cifra de caixeiros (arredor de 1.500 clientes por caixeiro), superior a España, cunha tendencia en ámbolos dous casos a intensificar o seu uso. No caso de BBVA, os datos son máis escasos, e queremos sinalar que entre 2007 e 2009 no conxunto de América Latina a súa instalación aumentou un 21\% fronte a un descenso do número en España nun 26\% para o mesmo período de tempo considerado. 


\subsection{Accionistas}

Son varios os aspectos que se teñen en conta sobre os accionistas:

-Perfil del accionista: a maior parte das accións do Banco Santander están en mans de investidores institucionais, un 63,98\% do total, fronte aos investidores individuais que posúen o 32,60\% das mesmas. Por outra banda, se o consideramos por áreas xeográficas a maior parte da propiedade da entidade está en mans europeas $(84,63 \%)$ fronte aos accionistas americanos (non se distingue entre zonas), que posúen o 15,10\% das mesmas. Isto quere dicir que malia a diversificación xeográfica, o negocio seguiu mantendo o control en Europa (os datos non distinguen entre España e Reino Unido, principais mercados europeos).

-Participación e comunicación co accionista: ponse o énfase en mellorar as vías de comunicación co accionista, así como a súa participación na xunta xeral de accionistas.

-Cotización en índices éticos: a cada vez maior preocupación dos clientes por temas medioambientais e sociais, que, por outra banda, levou á creación dos fondos de investimento socialmente responsables, fixo que se realizaran esforzos tanto por parte do Banco Santander como do BBVA para poder cumprir cos requisitos necesarios para que as súas accións puideran cotizar en índices bolsistas éticos.

\subsection{Empregados}

En canto aos empregados, a información publicada fai especial énfase nos aspectos como: definir o perfil profesional, xestión e desenvolvemento do talento, saúde e seguridade no traballo, igualdade de oportunidades, conciliación da vida familiar e profesional.

Con respecto á xestión do talento e o seu desenvolvemento formativo dentro da entidade cabe destacar o investimento en formación en ámbolos dous bancos. En canto á partida de gasto de persoal, o Banco Santander reduce o seu gasto por empregado ao mesmo tempo que o BBVA o aumenta, partindo os dous de posicións moi afastadas, chegan a se igualar en 2009.

A ter en conta neste apartado, están as políticas de contratación que levan a cabo as entidades. Nelas apóstase polo desenvolvemento das persoas con independencia do seu xénero, capacidade, idade, nacionalidade, orixe ou crenza para que todas elas teñan as mesmas posibilidades de desenvolver todo o seu potencial e aportalo para a consecución dos obxectivos da entidade (Memoria de responsabilidade do Banco Santander: 32). En todos os procesos de recursos humanos (selección, valoración, desenvolvemento e compensación) garantízase a igualdade de oportunidades.

A principal crítica que se pode facer con respecto á xestión dos empregados é a gran diferenza que existe en canto á súa distribución atendendo á categoría profesional dos mesmos. Atopouse que tanto no Banco Santander como no BBVA existe unha gran desproporción en canto ao número de mulleres que ocupa postos directivos e cargos intermedios ou técnicos, sendo elas na súa maior parte ocupadas en postos administrativos ou base. Nas súas memorias de responsabilidade, exponse a necesidade de acadar a igualdade de xénero, pero non se fala explicitamente de igualdade dentro de categorías profesionais. 


\subsection{Acción social e Investimento Socialmente Responsable (ISR)}

O obxectivo da acción social céntrase en contribuír ao desenvolvemento cultural, social e educativo das comunidades nas que exerce a súa actividade. Isto faise principalmente a través das vías que se resumen na táboa 4.

Dentro do apartado social hai que destacar as medidas a favor da mellora da cultura financeira e a implicación que en particular o Banco Santander ten coas universidades. En canto á educación financeira, é de vital importancia para ámabalas dúas entidades presentes en América Latina. Esta zona parte duns niveis de bancarización, así como de cultura financeira, moi baixos.

\section{Investimento Socialmente Responsable (ISR).}

O ISR vai gañando terreo e converteuse nunha alternativa de investimento atractiva e rendible fronte aos modos de investimento tradicional. Do que se trata con estes investimentos é de canalizar o aforro dos clientes, cada vez máis sensibilizados con aspectos sociais e medioambientais, cara proxectos nos que se garantiza un respecto por estes asuntos. O Banco Santander ofrece datos cualitativos sobre estes fondos prestando unha especial atención ao seu desenvolvemento en América Latina. Polo que respecta a esta zona, estes fondos teñen o seu maior desenvolvemento en Brasil.

En canto ao BBVA, realízase unha análise máis detallada e cuantitativa dos investimentos responsables. Estes creceron nos últimos anos con respecto ao volume total de fondos xestionados pola entidade pasando de representar o 1,38\% en 2007 ata un 2,92\% en 2009 experimentando deste xeito un crecemento do $111 \%$

Táboa 4. Medidas sociais adoptadas.

\begin{tabular}{|c|c|c|c|}
\hline Tipo de medida & Definición & $\begin{array}{c}\text { Banco } \\
\text { Santander }\end{array}$ & BBVA \\
\hline $\begin{array}{l}\text { Relacións estables co } \\
\text { terceiro sector. }\end{array}$ & $\begin{array}{l}\text { Diálogo coas ONGs. Na sede } \\
\text { operativa do banco promóvese } \\
\text { o Recanto solidario, onde teñen } \\
\text { lugar encontros entre os } \\
\text { empregados e as entidades sen } \\
\text { ánimo de lucro. }\end{array}$ & Arxentina. & \\
\hline $\begin{array}{l}\text { Produtos e servizos } \\
\text { sostibles. }\end{array}$ & $\begin{array}{l}\text { Facilitan o acceso ao mercado } \\
\text { financeiro de determinados } \\
\text { colectivos, contribuíndo á } \\
\text { bancarización dos países nos } \\
\text { que se está presente. }\end{array}$ & & \\
\hline Microcréditos. & $\begin{array}{lcr}\text { Ferramenta } & \text { de } & \text { inclusión } \\
\text { financeira } & \text { dos } & \text { máis } \\
\text { desfavorecidos. } & & \end{array}$ & Brasil e Chile. & $\begin{array}{l}\text { Perú, Colombia, } \\
\text { Porto Rico, Chile e } \\
\text { México. }\end{array}$ \\
\hline $\begin{array}{l}\text { Proxectos } \\
\text { desenvolvemento } \\
\text { educativo } \\
\text { memoria 2008). }\end{array}$ & & $\begin{array}{l}\text { Brasil, México, } \\
\text { Chile, Arxentina, } \\
\text { Colombia, Porto } \\
\text { Rico. }\end{array}$ & \\
\hline
\end{tabular}




\begin{tabular}{|l|l|l|}
\hline $\begin{array}{l}\text { Cooperación ao } \\
\text { desenvolvemento (datos } \\
\text { memoria 2008). }\end{array}$ & $\begin{array}{l}\text { Brasil, México, } \\
\text { Chile,Arxentina, } \\
\text { Colombia e } \\
\text { Porto Rico. }\end{array}$ \\
\hline $\begin{array}{l}\text { Proxectos de } \\
\text { coparticipación cos } \\
\text { empregados e clientes } \\
\text { (datos memoria 2008 e }\end{array}$ & $\begin{array}{l}\text { Brasil, México, } \\
\text { Chile, Arxentina, } \\
\text { 2009). }\end{array}$ & $\begin{array}{l}\text { Colombia e } \\
\text { Porto Rico. }\end{array}$ \\
\hline
\end{tabular}

Fonte: elaboración propia a partir das memorias de responsabilidade do Banco Santander e do BBVA.

\subsection{Provedores}

Nas memorias de responsabilidade de ámbolos dous bancos maniféstase o seguinte: (i) a relación comercial cos provedores realízase con aqueles que se atopan homologados, (ii) o $95 \%$ dos provedores son locais, trátanse de empresas que operan no mesmo eido xeográfico no que se realiza a compra e a facturación e, (iii) as adxudicacións de contratos e selección de provedores permiten a igualdade de oportunidades entre os provedores competidores entre eles, e destacan pola súa obxectividade e a transparencia.

\subsection{Medioambiente}

En 2009 asináronse acordos de financiamento para a xeración de enerxías renovables (parques eólicos, plantas fotovoltaicas, centrais termosolares e minihidráulicas en Brasil e México).

\subsection{Imaxe e reputación}

A reputación corporativa e a imaxe de marca son dous aspectos esenciais a ter en conta polas EE.FF., tratando este asunto nas súas memorias de responsabilidade, onde se ve que son unha prioridade estratéxica para elas. Conforme afirma o Banco Santander na súa memoria de responsabilidade de 2009 (p. 13) "o que se procura é que a suma de imaxe de marca, resultados económicos, actuación responsable e o modelo de negocio conflúan nunha boa reputación internacional posicionándoa como unha das mellores empresas".

\section{CONCLUSIÓNS}

Os cambios económicos e sociais acontecidos nas últimas décadas leváronos a reformular hoxe en día o papel que deben xogar as empresas dentro da sociedade. Os procesos de desregularización, deslocalización, liberalización económica, privatización, e, en xeral, todas as transformacións que levan ao proceso de globalización da economía e á internacionalización das empresas, fixeron que pasasen de ser meros centros de traballo a converterse nun aspecto central da vida das persoas, sen se limitar á produción e venda de produtos e servizos, senón que en moitas ocasións incrementan a súa presenza social mediante o patrocinio e a subministración de diversos produtos e servizos.

O proceso de globalización económica estivo protagonizado por unha serie de elementos característicos: o crecemento internacional do sector servizos, consecuencia lóxica da terciarización da economía nos países desenvolvidos; o aumento da importancia do papel da empresa privada como consecuencia do aumento das súas dimensións con repercusión 
da súa actividade internacionalmente; e, finalmente, a esixencia por parte da sociedade dun comportamento máis responsable ás empresas.

O sector financeiro español debería ser un claro exemplo de adaptación a este novo papel que xoga hoxe en día a empresa privada, reunindo cada unha das características que definen o papel da empresa na nova economía. Como parte do sector servizos, foi protagonista, sendo un dos sectores con maior proxección internacional nos últimos anos, sendo especialmente relevante o impacto da banca española en Iberoamérica. Por outra banda, o papel da banca é chave non só para o desenvolvemento da economía como elemento regulador e distribuidor dos fluxos financeiros, senón que é un dos sectores que máis implicado está na vida cotiá das persoas, o nivel de bancarización da sociedade é moi elevado; unido ao anterior, as entidades financeiras asumen unha gran responsabilidade fronte á sociedade no seu conxunto, exemplo diso foi a crise financeira recente, e conscientes diso, as entidades foron pioneiras na asimilación dentro da súa estratexia de negocio da filosofía de responsabilidade social, servindo de exemplo ao resto de sectores da actividade.

Porén, as iniciativas concretas xurdidas coa finalidade de fomentar a implantación da RSC nas EE.FF. son moi diversas, podendo chegar a ser moi heteroxéneas entre elas. Malia estar asistindo nos últimos anos a un impulso no número de publicacións relativas a RSC, parece pouco frecuente que se ofreza información sobre os impactos indirectos de RSC das operacións bancarias, ou o que é o mesmo, os criterios de sustentabilidade que a banca ten establecidos para decidir sobre o financiamento de proxectos de investimento, da súa contribución ao desenvolvemento sostible a través dos recursos financeiros asignados a tales fins.

Estes informes sobre RSC ocúpanse principalmente dos impactos internos das operacións bancarias e tamén das actividades de tipo filantrópico a favor da colectividade ou de grupos desfavorecidos que precisan atención especial.

\section{BIBLIOGRAFÍA}

BALLESCÁ RAMÍREZ, M. (2007): “La banca extranjera en América Latina: resultado de su desempeño". Espiral, Estudios sobre estado y sociedad, Vol. XIV, no 40 Septiembre Diciembre, p. 123-156.

BECKER, F. (2002): Latinoamérica: una oportunidad para la empresa española. ICE, abril a mayo 2002: Madrid.

CALVO, A., PAREJO, J. A.; RODRÍGUEZ, L.; CUERVO, A. (2010): Manual del sistema financiero español. Ariel: Madrid.

CEA MOURE, R. (2010): La responsabilidad social corporativa en las entidades bancarias de la Unión Europea. Análisis empírico y propuesta de modelo normalizado. Tesis doctoral, Universidad Autónoma de Madrid.

CHEVALIER, J.M. (1995): L'Économie industrielle des Stratégies d'entrerprises. Montchrestien. Domat Économie: París.

COMISIÓN EUROPEA (2004): european multistakeholder fórum on CRS. Final results \& recomendations. $\mathrm{n}$ - 29, junio.

DE LA CUESTA, M. (2004): “La responsabilidad social en el sector bancario: una propuesta de indicadores para medir su contribución social”, Cuadernos de información económica, Vol. 180, p. 79-85. 
DE LA CUESTA, M. (2006): "Responsabilidad social del sector bancario: su contribución a un desarrollo más sotenible”, Papeles de economía Española, Vol. 108, p. 173-189.

DUNNING, J.H. (1994): "The eclectic paradigm of international production: a restatement and some possible extensions", Journal of international business studies, Vol. 1, no 19, p. 1-31.

DURÁN HERRERA, J.J.; LAMOTHE FERNÁNDEZ, P. (1991): “El proceso de multinacionalización de la banca Española”, ICE, Vol. 15, nํ 692, p. 187-205.

GLOBAL REPORTING INITIATIVE (2002). Suplemento sobre el sector de servicios financieros: Desempeño social.

GLOBAL REPORTING INITIATIVE (2005): Suplemento sobre el sector de servicios financieros: Desempeño medioambiental.

HIGGINS, C.; LARRINAGA, C. (2014): "Sustainability reporting: insights from institutional theory", Bebbington, J., Unerman, J. y O'Dwyer, B., Sustainability Accounting and Accountability. Routledge, p. 273-285.

MINISTERIO DE ASUNTOS EXTERIORES Y COOPERACIÓN (2010): http:/ / www.aecid.es/ web/ es/ noticias/ 2009/04_Abril/2009_04_03_informe_cad_espana. html

MINISTERIO DE TRABAJO Y ASUNTOS SOCIALES (2005): I, II y III sesión de trabajo del foro de expertos en RSC, Secretaría General de la Dirección General de Economía Social, MTAS, Madrid.

MONEVA, J.M. (2005). “Información corporativa y desarrollo sostenible”, Economistas, Vol. 23 , no 106, p. 70-78.

MUÑOZ, Ma‥j; FERNÁNDEZ A.; DE LA CUESTA, M. (2004): Responsabilidad social en el sistema bancario: una primera aproximación de evaluación para el caso español. EBEN. Papeles de Ética, Economía y Dirección, (12), p. 1-12.

OHMAE, K. (1991): El mundo sin Fronteras. Poder y estrategia en la economía entrelazada. McGraw-Hill. Londres.

ORTIZ VICENTE, J.; CORDERO GARCÍA, G. (2007): La responsabilidad social corporativa en España. Fundación alternativas: Madrid.

RODRIGUEZ-GUTIERREZ, P., SANCHEZ-CAÑIZARES, S., FUENTES-GARCÍA, F.J.(2017) "Determinantes de los indicadores de la calidad divulgativa de la memoria de sostenibilidad: El caso de la banca española”. Revista Galega de Economía, Vol. 26-2

Revista Galega de Economía: http:/ / www.usc.es/ econo/ RGE/ benvidag.htm 